\title{
Inhibition of Lck enhances glucocorticoid sensitivity and apoptosis in lymphoid cell lines and in chronic lymphocytic leukemia
}

\author{
MW Harr ${ }^{1}$, PF Caimi ${ }^{1,4}$, KS McColl ${ }^{1}$, F Zhong ${ }^{1}$, SN Patel ${ }^{1,4}$, PM Barr ${ }^{1,4}$ and CW Distelhorst ${ }^{\star, 1,2,3,4}$
}

Glucocorticoids are used as part of front-line therapy to treat lymphoid malignancy because of their remarkable ability to induce apoptosis. Yet, in T cells, glucocorticoid-induced apoptosis is readily inhibited by lymphocyte activation and signaling. We have previously shown that the Src family kinase, Lck (lymphocyte cell-specific tyrosine kinase), which is predominantly expressed in T cells, interacts with IP3 receptors to facilitate calcium signaling. Here, we discovered that dexamethasone downregulates Lck, which, in turn, suppresses lymphocyte activation by inhibiting pro-survival calcium oscillations. Moreover, stable expression of shRNAs that selectively targeted Lck or treatment with the Src inhibitor dasatinib (BMS-354825) enhanced apoptosis induction by dexamethasone. To investigate the effect of Lck inhibition in a primary leukemia model, we employed chronic lymphocytic leukemia (CLL) cells that aberrantly expressed Lck and were relatively insensitive to dexamethasone. Lck expression was correlated with resistance to dexamethasone in CLL cells, and its inhibition by dasatinib or other inhibitors markedly enhanced glucocorticoid sensitivity. Collectively, these data indicate that Lck protects cells from glucocorticoid-induced apoptosis and its inhibition enhances sensitivity to dexamethasone. Small-molecule inhibitors of Lck, such as dasatinib, may function to reverse glucocorticoid resistance in some lymphoid malignancies.

Cell Death and Differentiation (2010) 17, 1381-1391; doi:10.1038/cdd.2010.25; published online 19 March 2010

Glucocorticoid hormones and their synthetic derivatives, prednisone and dexamethasone, readily induce cell killing in lymphocytes. ${ }^{1-3}$ Glucocorticoid-induced cell death is primarily mediated by a receptor-dependent mechanism that results in apoptosis or necrosis. ${ }^{4-6}$ During this process, the ligandbound glucocorticoid receptor (GR) translocates to the nucleus to transactivate or repress gene transcription. ${ }^{7,8}$ Thus, glucocorticoid sensitivity may be characterized, in part, by transcriptional changes in genes that regulate the cell death process. ${ }^{5}$

In T cells, glucocorticoid-induced apoptosis is antagonized by the activation of T cell receptor (TCR) signaling. ${ }^{9-12}$ After TCR activation, the lymphocyte cell-specific tyrosine kinase (Lck) translocates to the cell surface and phosphorylates immunoreceptor tyrosine activation motifs on the TCR. ${ }^{13,14}$ This results in a phosphorylation cascade that leads to the activation of phospholipase $\mathrm{C} \gamma$, generation of IP3, and intracellular calcium release from IP3 receptor channels. ${ }^{15}$ In addition, we have recently shown that Lck interacts with IP3 receptors to positively regulate IP3-mediated calcium signals. ${ }^{16}$

Calcium, in turn, functions to activate calcineurin to dephosphorylate NFAT, thereby inducing its translocation to the nucleus and stimulating transcription of proinflammatory cytokines. ${ }^{17}$ Importantly, calcium-dependent activation of calcineurin was shown to be an integral step in the inhibition of glucocorticoid-induced apoptosis. ${ }^{18}$ In addition, glucocorticoids also suppress T-cell activation by rapidly inhibiting Src kinases Fyn and Lck, intracellular calcium release, and transcription of proinflammatory cytokines. ${ }^{19-23}$ Consequently, these events provide a negative regulatory mechanism whereby lymphocyte activation rescues cells from glucocorticoid-induced apoptosis, and conversely, glucocorticoids inhibit downstream TCR-dependent signaling.

Because of its role in regulating cell proliferation and survival, Lck, similar to Src, acts as a protooncogene to facilitate cellular transformation, ${ }^{24}$ and is overexpressed in Burkitt and non-Hodgkin's B-cell lymphoma, as well as myeloid and lymphocytic leukemias. ${ }^{25-29}$ Although Lck has previously been shown to block apoptosis induced by TCR crosslinking or proinflammatory cytokines, ${ }^{30}$ it has not been investigated whether Lck directly affects glucocorticoidinduced apoptosis. On conducting microarray analysis of normal and malignant $T$ cells, we discovered that dexamethasone downregulates Lck in a manner that is sufficient to inhibit TCR signaling. Moreover, glucocorticoid-induced apoptosis was enhanced in cells that stably expressed Lck shRNAs or were treated with the Src inhibitor dasatinib. In contrast, primary chronic lymphocytic leukemia (CLL) cells that undergo ligand-independent calcium signaling aberrantly expressed Lck and were completely resistant to its

\footnotetext{
${ }^{1}$ Division of Hematology and Oncology, Department of Medicine, Case Western Reserve University, Cleveland, Ohio, USA; ${ }^{2}$ Department of Pharmacology, Case Western Reserve University, Cleveland, Ohio, USA; ${ }^{3}$ Case Comprehensive Cancer Center, Case Western Reserve University, Cleveland, Ohio, USA and ${ }^{4}$ University Hospitals of Cleveland, Cleveland, Ohio, USA

${ }^{*}$ Corresponding author: CW Distelhorst, Division of Hematology and Oncology, Department of Medicine, Case Western Reserve University School of Medicine and University Hospitals of Cleveland, 10900 Euclid Avenue, Wolstein Research Building 3-133, Cleveland, Ohio 44106-7285, USA. Tel: +216 368 4546;

Fax: + 216368 8919; E-mail: cwd@ case.edu

Keywords: glucocorticoids; dexamethasone; calcium; apoptosis; T-cell receptor; Lck

Abbreviations: CLL, chronic lymphocytic leukemia; Lck, lymphocyte cell-specific tyrosine kinase

Received 25.9.09; revised 27.1.10; accepted 10.2.10; Edited by M Federici ; published online 19.3.10
} 
downregulation by dexamethasone. Although CLL cells were relatively insensitive to glucocorticoids, Lck inhibition significantly enhanced response to dexamethasone, suggesting a novel means to reverse glucocorticoid resistance in lymphoid malignancy.

\section{Results}

Dexamethasone downregulates Lck expression to inhibit TCR signaling. In our effort to identify candidate genes that were regulated by glucocorticoids, we conducted microarray analysis of dexamethasone-treated thymocytes, S49.A2, and WEHI7.2 murine T-lymphoma cells. Each of these $\mathrm{T}$-cell populations have shown to be highly sensitive to the effects of dexamethasone. ${ }^{5}$ Microarray analysis revealed several genes that were upregulated by dexamethasone and that contributed, in part, to the induction of apoptosis. ${ }^{31,32}$ Interestingly, Lck was discovered to be among a cluster of genes that were downregulated by dexamethasone in each of these T-cell populations. In primary thymocytes, Lck mRNA levels were downregulated by over $80 \%$ (Figure 1). Among 57 genes that were downregulated by greater than or equal to twofold, excluding those that were hypothetical or unknown, only eight were downregulated by a stronger degree of magnitude. To confirm that Lck was in fact downregulated by glucocorticoids in normal and malignant $T$ cells, we measured its expression by real-time quantitative PCR (qPCR) (Figure 2a and b) and then by western blotting in WEHI7.2 cells, primary thymocytes, and the T-cell leukemia line CEMC7 (Figure 2c-e). Simultaneous treatment with dexamethasone and the GR antagonist RU486 prevented Lck downregulation, indicating that it is repressed by a GRdependent mechanism (Figure 2c).
To determine whether the downregulation of Lck by dexamethasone was sufficient for the induction of apoptosis, we knocked down Lck expression in WEHI7.2 cells using a lentiviral shRNA approach. Results from these experiments showed no differences in baseline apoptosis between control and Lck shRNA cells $(3.9 \pm 0.49 \%$ compared with $4.7 \pm$ $0.56 \%$, respectively, $P=0.33$ ), indicating that downregulation of Lck alone is not sufficient for apoptosis to occur. Similar levels of apoptosis were also observed in Lck and Fyn double knockdown cells, ruling out the possibility that another Src family member (for example, Fyn) compensates for decreased expression of Lck (data not shown).

In contrast, we found that the downregulation of Lck by dexamethasone was sufficient to inhibit both ligand-independent (unstimulated) and anti-CD3-induced calcium oscillations in WEHI7.2 cells (Figure $3 a-c$ ). To mimic the effect of dexamethasone on Lck, we transiently knocked down its expression using gene-specific siRNAs. When Lck expression was decreased by $\geqslant 70 \%$, calcium oscillations were reduced in a similar manner as with dexamethasone treatment (Figure $3 d-f)$. Together, these data indicate that the downregulation of Lck is sufficient for glucocorticoid-mediated inhibition of TCR-induced calcium signaling but not apoptosis.

On the basis of these findings, we predicted that the Src kinase inhibitor, dasatinib, would also suppress TCR signaling by inhibiting Lck activity. The ability of dasatinib to inhibit T-cell activation has been previously shown in normal peripheral blood lymphocytes. ${ }^{33}$ We determined that $100 \mathrm{nM}$ dasatinib was the optimal concentration for inhibiting Lck phosphorylation at its activating tyrosine residue (Y394), given that phosphorylation at this site was inhibited by $>90 \%$ (Figure 4a). As anticipated, dasatinib markedly inhibited TCR signaling, as assessed by anti-CD3-induced calcium

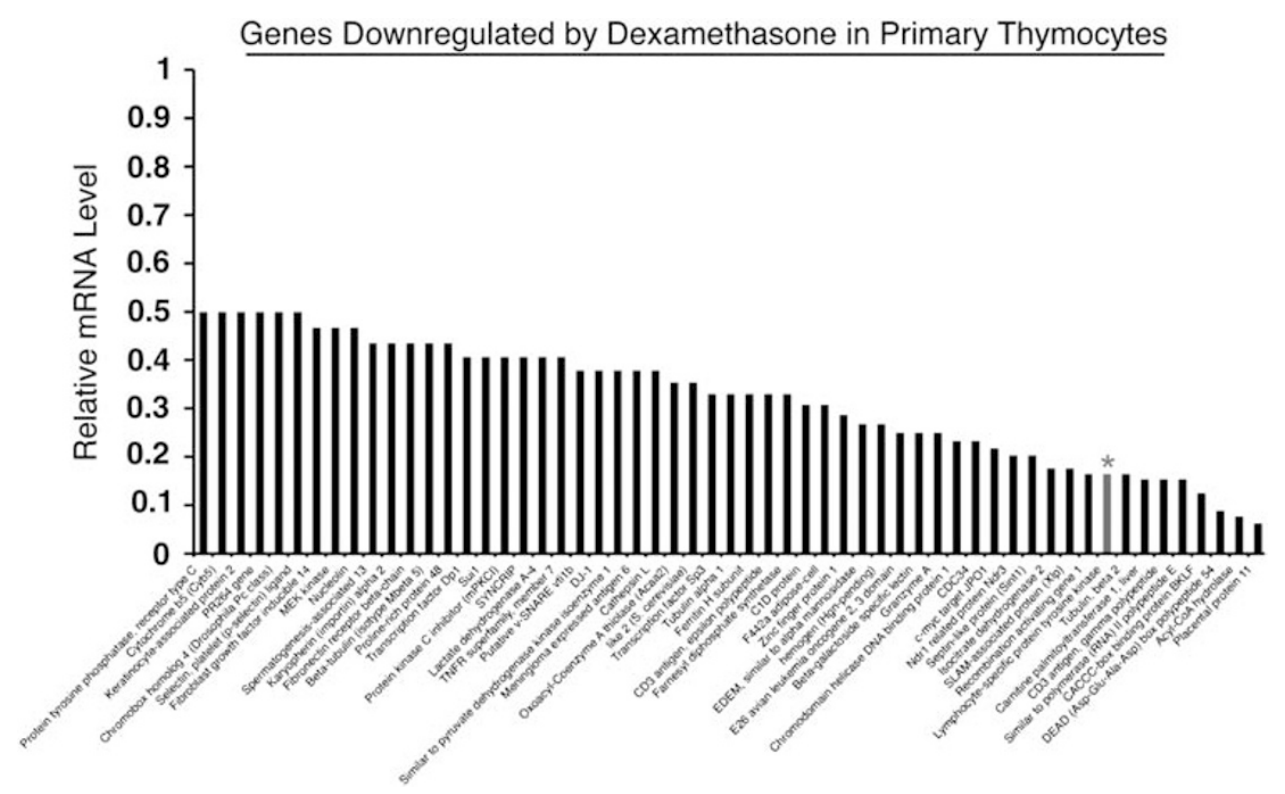

Figure 1 Microarray analysis of genes downregulated by dexamethasone. Primary thymocytes were harvested from adult B6 mice, treated with vehicle (0.1\% ethanol) or $10^{-6} \mathrm{M}$ dexamethasone for $12 \mathrm{~h}$, and subjected to microarray analysis as previously described (see Materials and Methods). The bar graph shows the extent of downregulation relative to vehicle-treated cells. Lck (designated with an asterisk) had a signal Log $_{2}$ ratio of $(-) 2.6$ indicating repression by a magnitude of sixfold. Lck was also downregulated in WEHI7.2 and S49A.2 murine T-cell lines 

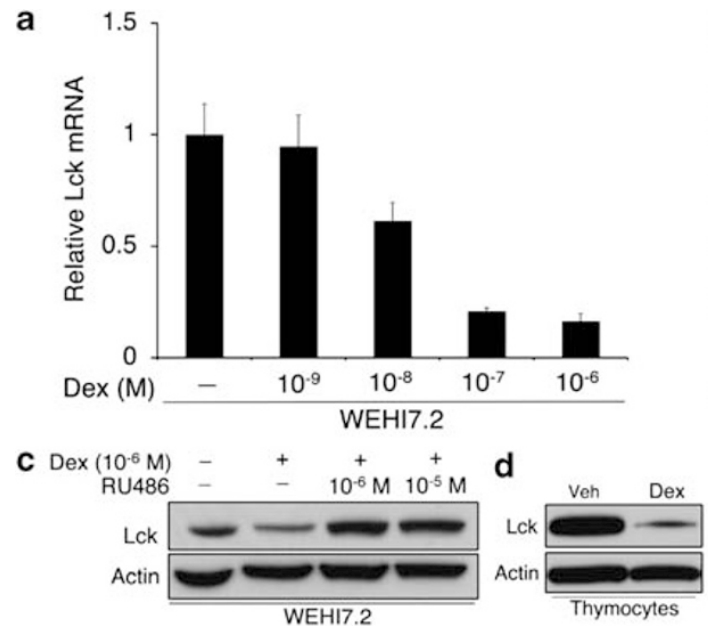

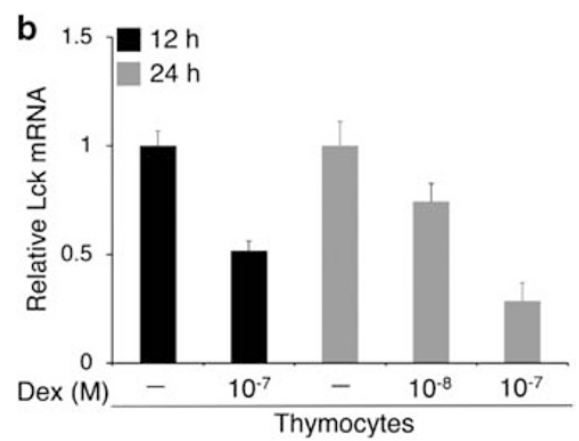

e

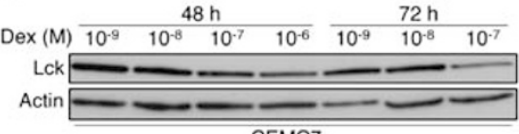

CEMC7

Figure 2 Dexamethasone downregulates expression of Lck. (a) WEHI7.2 cells were treated with vehicle or varying concentrations of dexamethasone for $24 \mathrm{~h}$. Lck mRNA was measured by real-time PCR. Values represent triplicate measurements and are relative to the vehicle-treated sample. $\beta$-actin was used as an endogenous control for each PCR reaction. (b) Primary thymocytes $\left(5.0 \times 10^{6}\right.$ cells per ml) were harvested from adult B6 mice and treated with vehicle or dexamethasone for 12 and $24 \mathrm{~h}$. Lck mRNA was measured by real-time PCR as described above. (c) WEHI7.2 cells were treated with vehicle or $10^{-6} \mathrm{M}$ dexamethasone with and without the glucocorticoid receptor antagonist RU486 at equal and excess concentrations for $24 \mathrm{~h}$. Lysates were subjected to western blotting for Lck. (d) Thymocytes were treated with vehicle or $10^{-8} \mathrm{M}$ dexamethasone for $12 \mathrm{~h}$ and subjected to western blotting for Lck. (e) CEMC7 cells (T-ALL) were treated with varying concentrations of dexamethasone for 48 and $72 \mathrm{~h}$ and subjected to western blotting for Lck. $\beta$-Actin was used as a loading control. Data are representative of multiple independent experiments. Error bars indicate the difference between maximum and mean values from triplicate measurements

a

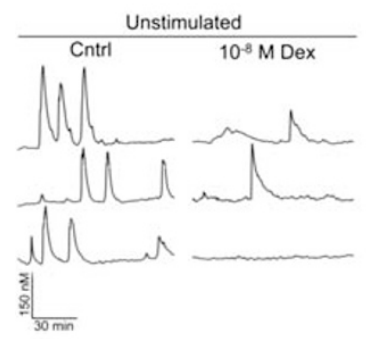

b
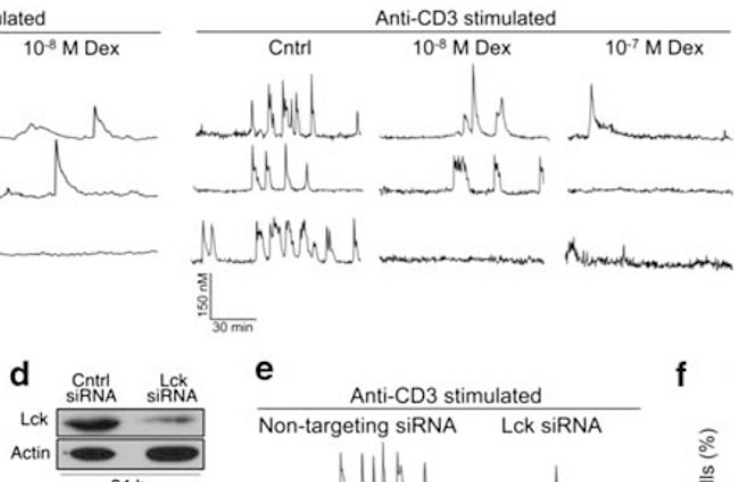

$24 \mathrm{~h}$ e

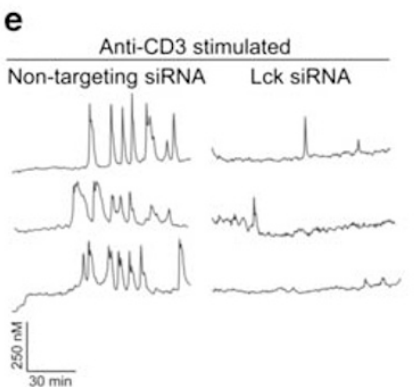

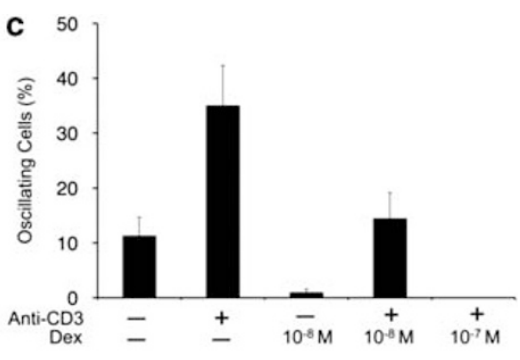

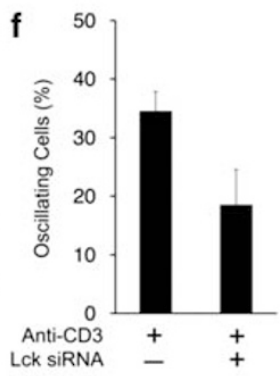

Figure 3 Dexamethasone downregulates Lck to inhibit TCR signaling. (a) Single cell calcium measurements in unstimulated WEHI7.2 cells treated with $10^{-8} \mathrm{M}$ dexamethasone for $20 \mathrm{~h}$. Representative traces are shown. (b) Cells were treated as in a, but stimulated with anti-CD3 antibody $(2 \mu \mathrm{g} / \mathrm{ml}) 1 \mathrm{~min}$ into the calcium trace. (c) Quantification of oscillating cells ( $\geqslant$ three spikes) in a and b. (d) Cells were transfected with control (nontargeting) siRNAs or those that specifically target Lck and incubated for $24 \mathrm{~h}$. Lysates were subjected to western blotting for Lck. (e) Representative calcium traces in nontargeting or Lck siRNA-transfected cells after stimulation with anti-CD3 $(2 \mu \mathrm{g} / \mathrm{ml})$. (f) Quantification of oscillating cells in e. Data are representative of multiple independent experiments. Error bars represent the S.E.M.

oscillations as well as by MEK and ERK phosphorylation (Figure 4b-d).

Dexamethasone and dasatinib synergistically inhibit TCR signaling. Although dasatinib and dexamethasone both regulate Lck by distinct mechanisms, we asked whether these agents might function synergistically to inhibit phosphorylation of Src family kinases. Importantly, glucocorticoids have also been shown to rapidly inhibit phosphorylation of both Lck and Fyn by a nongenomic mechanism. ${ }^{22,23}$ Thus, both dexamethasone and dasatinib are capable of inhibiting Lck phosphorylation status without 
affecting mRNA or protein levels, respectively. We found that both dexamethasone and dasatinib reduced Lck phosphorylation at Y394; however, inhibition was substantially greater in the presence of dasatinib (Figure $5 \mathrm{a}$ and b) and phosphorylation could not be detected in cells treated with both agents. Interestingly, both dexamethasone and dasatinib

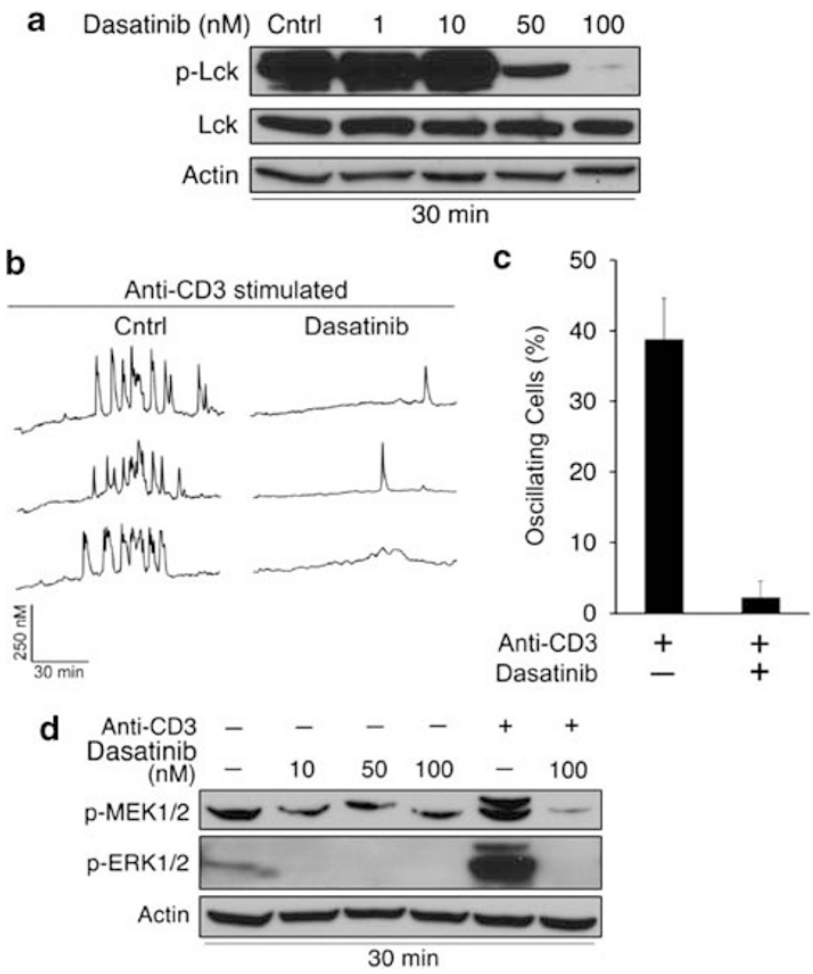

Figure 4 Dasatinib inhibits Lck phosphorylation and TCR signaling. (a) WEHI7.2 cells were treated with vehicle $(0.01 \%$ DMSO) or dasatinib for $30 \mathrm{~min}$. Phosphorylated (Y394) and total Lck levels were measured by western blotting. $\beta$-Actin was used as a loading control. (b) Single cell calcium measurements in WEHI7.2 cells treated with $100 \mathrm{nM}$ dasatinib for $30 \mathrm{~min}$ and stimulated with anti-CD3 antibody $(2 \mu \mathrm{g} / \mathrm{ml}) 1 \mathrm{~min}$ into the calcium trace. Representative traces are shown. (c) Quantification of oscillating cells ( $\geqslant$ three spikes) in b. (d) Cells were treated with dasatinib as in a, and phospho-MEK and ERK levels were measured by western blotting. Cells were stimulated with anti-CD3 $(2 \mu \mathrm{g} / \mathrm{ml})$ for $5 \mathrm{~min}$ to induce MEK and ERK phosphorylation. Data are representative of multiple independent experiments. Error bars represent the S.E.M. alone were sufficient to inhibit Lck phosphorylation at Y505, the C-terminal negative regulatory site (Figure 5a). Total levels of Lck and Fyn protein were downregulated by dexamethasone and substantially reduced in the presence of dexamethasone and dasatinib (Figure 5a). These data suggest that dasatinib and dexamethasone cooperate synergistically to inhibit Src activity and expression. In support of this observation, we also noted that downstream TCR signaling proteins were affected in a similar manner. For example, ZAP-70 expression was downregulated by dexamethasone and dasatinib, as well as TCR adapter proteins LAT and SLP-76 (Figure 5c). Downstream MAP kinase signaling was also inhibited by the combination of dexamethasone and dasatinib to a greater extent than either agent alone, as depicted by the loss in MEK1/2 phosphorylation (Figure 5c).

Lck inhibition enhances glucocorticoid sensitivity and apoptosis. Because TCR signaling antagonizes glucocorticoid-induced apoptosis, ${ }^{9-11}$ we investigated whether the combination of dexamethasone and dasatinib, which profoundly abrogates TCR signaling (Figure 5), would enhance overall cytotoxicity to dexamethasone. Accordingly, we observed that the $I C_{50}$ for dexamethasone decreased by greater than fourfold when cells were also exposed to $100 \mathrm{nM}$ dasatinib (Figure 6a). Although dasatinib alone was not cytotoxic in these cells (Figure 6a, b, and d), the combination of dexamethasone and dasatinib markedly enhanced glucocorticoid-induced apoptosis (Figure $6 b-d$ ). To determine whether the effect of dasatinib was specifically due to the inhibition of Lck, we tested whether WEHI7.2 cells, stably transduced with Lck shRNAs, would respond to dexamethasone in a similar manner. As shown in Figure 6e, Lck expression was markedly downregulated in cells transduced with shRNA and glucocorticoid-induced apoptosis was elevated relative to control cells (Figure 6e). Collectively, these data indicate that Lck protects cells from glucocorticoidinduced apoptosis, and that Lck inhibition sensitizes T cells to the apoptotic effects of dexamethasone.

Lck expression correlates with resistance to dexamethasone in CLL cells. Because Lck inhibition by shRNAs or dasatinib enhanced glucocorticoid sensitivity in T cells, we tested whether Lck inhibition would also sensitize primary leukemia cells to dexamethasone. When conducting these
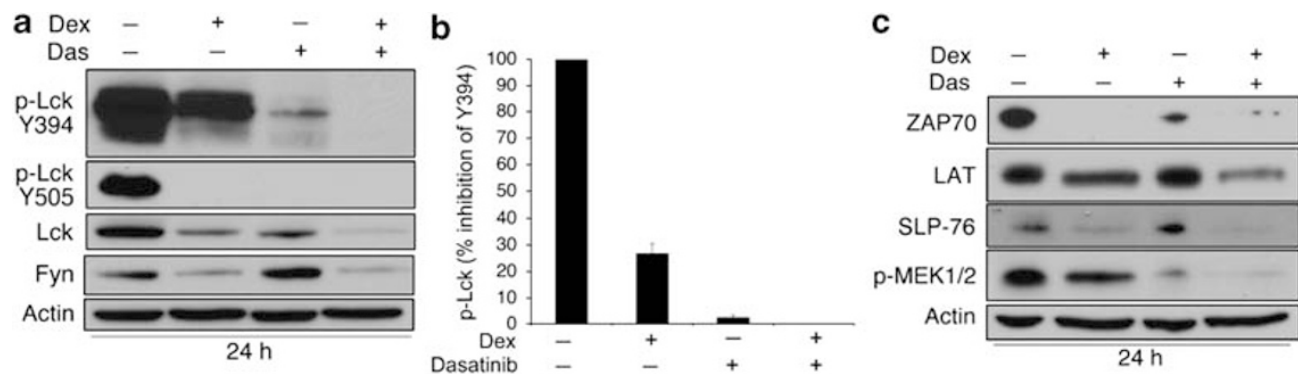

Figure 5 Dexamethasone and dasatinib synergistically inhibit TCR signaling. (a) WEHI7.2 cells were treated with vehicles $\left(0.1 \%\right.$ ethanol and $0.01 \%$ DMSO), $10^{-6} \mathrm{M}$ dexamethasone, $100 \mathrm{nM}$ dasatinib, or both for $24 \mathrm{~h}$. Phospho-Lck (Y394 and Y505), total Lck, and Fyn levels were measured by western blotting. $\beta$-Actin was used as a loading control. (b) Quantification of phospho-Lck (Y394) after treatment with dexamethasone or dasatinib. (c) Cells were treated as in a and downstream TCR proteins ZAP-70, LAT, SLP-76, and phospho-MEK were measured by western blotting. Data are representative of multiple independent experiments. Error bars represent the S.E.M. 


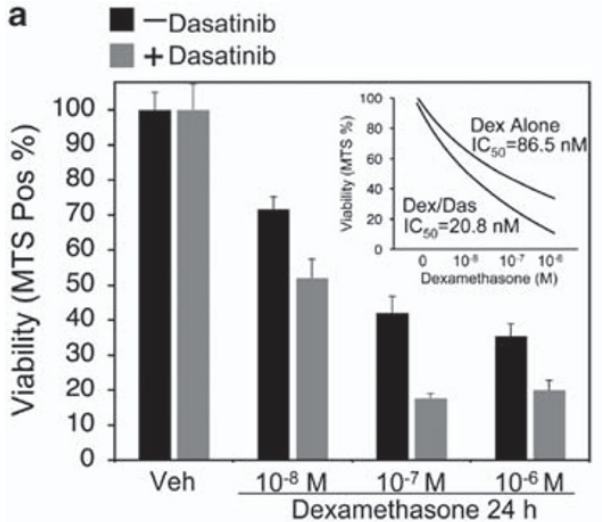

b

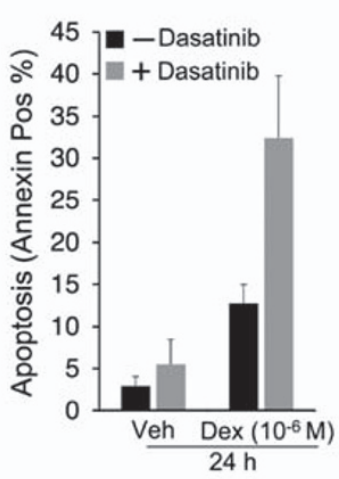

C

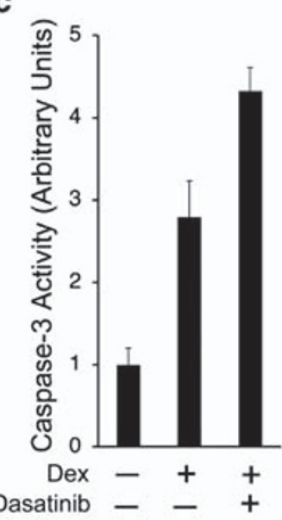

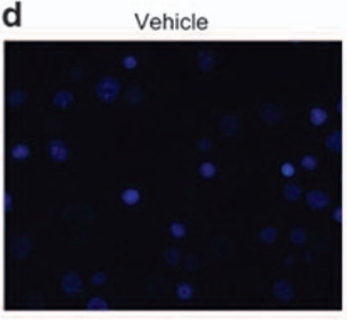

$10^{-6} \mathrm{M}$ Dex

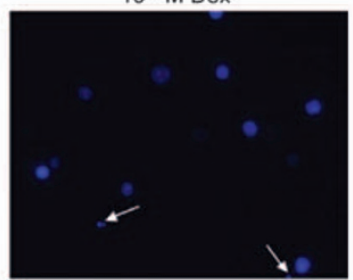

Dasatinib

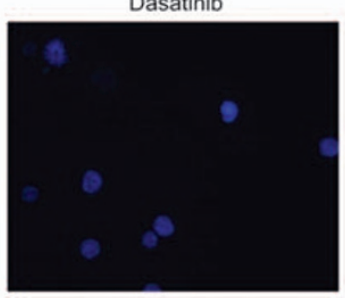

$10^{-6} \mathrm{M}$ Dex + Dasatinib

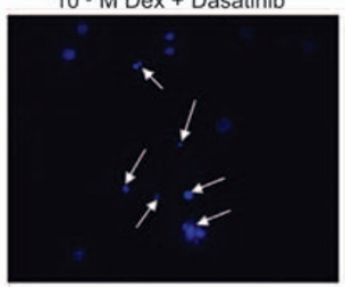

e

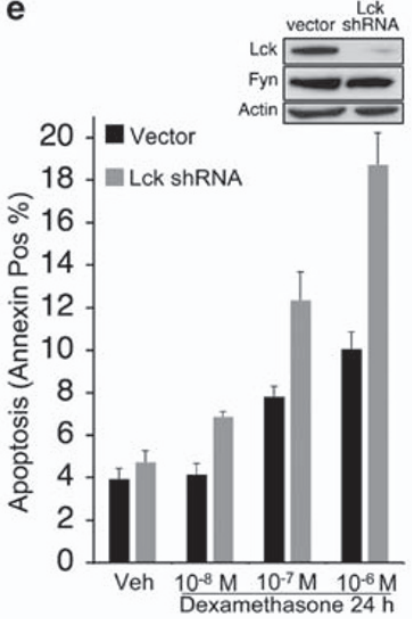

Figure 6 Lck inhibition enhances glucocorticoid sensitivity and apoptosis. (a) WEHI7.2 cells were treated with vehicles $\left(0.1 \%\right.$ ethanol and $0.01 \%$ DMSO), $10^{-6} \mathrm{M}$ dexamethasone, $100 \mathrm{nM}$ dasatinib, or both for $24 \mathrm{~h}$. Cells were transferred onto a 96-well plate, treated with MTS reagent, and incubated for $3 \mathrm{~h}$. Values represent the percent of control (Abs at $490 \mathrm{~nm}$ ) and were obtained in triplicate. Inset, IC ${ }_{50}$ for dexamethasone treatment alone or dexamethasone and dasatinib. (b) Cells were treated as in a and apoptosis was measured by flow cytometric analysis of Annexin V-positive cells. (c) Cells were treated as in a, lysed in non-denaturing buffer, and Caspase-3 activity was assessed by adding Ac-DEVD-AMC fluorogenic substrate. Values represent fold increase in fluorescence and were obtained in triplicate. (d) Cells were treated as in a, stained with Hoechst 33342, and visualized by epifluorescence microscopy (Zeiss axiovert S100) using a Zeiss $\times 40$ fluorescent oil objective. Representative fields are shown for each treatment. Apoptotic nuclear morphology is indicated by white arrows. (e) WEHI7.2 cells were transduced with lentiviral shRNAs to selectively target Lck. Top: western blot for Lck and Fyn in cells transduced with empty vector or Lck shRNA. Bottom: control or Lck knockdown cells $\left(2.0 \times 10^{5}\right.$ cells per ml) were treated with vehicle $(0.1 \%$ ethanol) or dexamethasone for $24 \mathrm{~h}$. Apoptosis was measured as in $\mathbf{b}$. Data are representative of multiple independent experiments. Error bars represent the S.E.M.

experiments, we used CLL cells as a model of lymphoid malignancy because B-CLL (i) is the most commonly diagnosed leukemia in the western hemisphere, (ii) is routinely treated with glucocorticoids, although responses are profoundly inferior to that of acute lymphoblastic leukemia (ALL), ${ }^{1-3,34}$ (iii) has aberrant expression of $\mathrm{Lck}^{29}$ and (iv) shows characteristics of ligand-independent BCR signaling. ${ }^{35,36}$

To confirm that CLL cells undergo ligand-independent signaling, we measured calcium responses in cells that were isolated from three individuals. Typical pro-survival calcium oscillations were detected in the absence of ligand stimulation, suggesting that these cells undergo constitutive BCR activation and signaling (Figure 7a). We then determined that ex vivo responses to dexamethasone, in terms of overall cell killing, were significantly weakened relative to glucocorticoidsensitive $T$ cells (Figure $7 \mathrm{~b}$ ). Lack of response to dexamethasone was also shown in MEC1 cells, a prolymphocytoid CLL cell line (Figure 7c). After measuring expression of Src kinases Lck, Lyn, and Fyn by real-time qPCR, we found that all three genes were expressed in CLL cells. However, only Lck was aberrantly elevated in all CLL samples $(N=10)$ compared with normal $B$ cells by over one order of magnitude (Figure $7 d$ and e). Both normal thymocytes and malignant $\mathrm{T}$-cell lines were included in the analysis as positive controls. Notably, several CLL samples expressed Lck at levels greater or equal to these T-cell populations (Figure 7d). Lck was also elevated in peripheral blood lymphocytes isolated from a patient with circulating marginal zone lymphoma (Figure 7d). Further analysis of protein levels confirmed that Lck was readily detectable in CLL but not in normal $B$ cells (Figure 7f), whereas Fyn and Lyn were detectable in both normal and malignant cells (data not shown). These data confirm that Lck is aberrantly expressed in CLL cells that undergo ligand-independent signaling and are resistant to the cytotoxic effects of glucocorticoids. Accordingly, we observed a significant negative correlation between Lck expression 
a

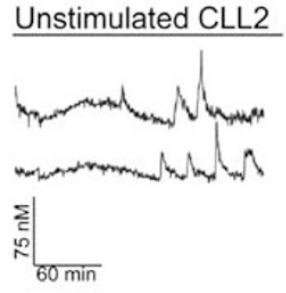

d
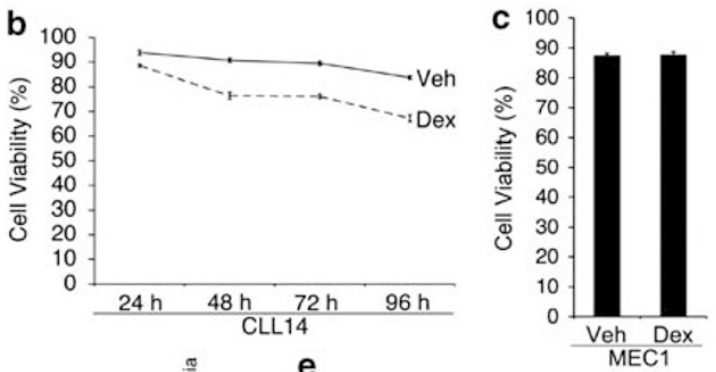

e
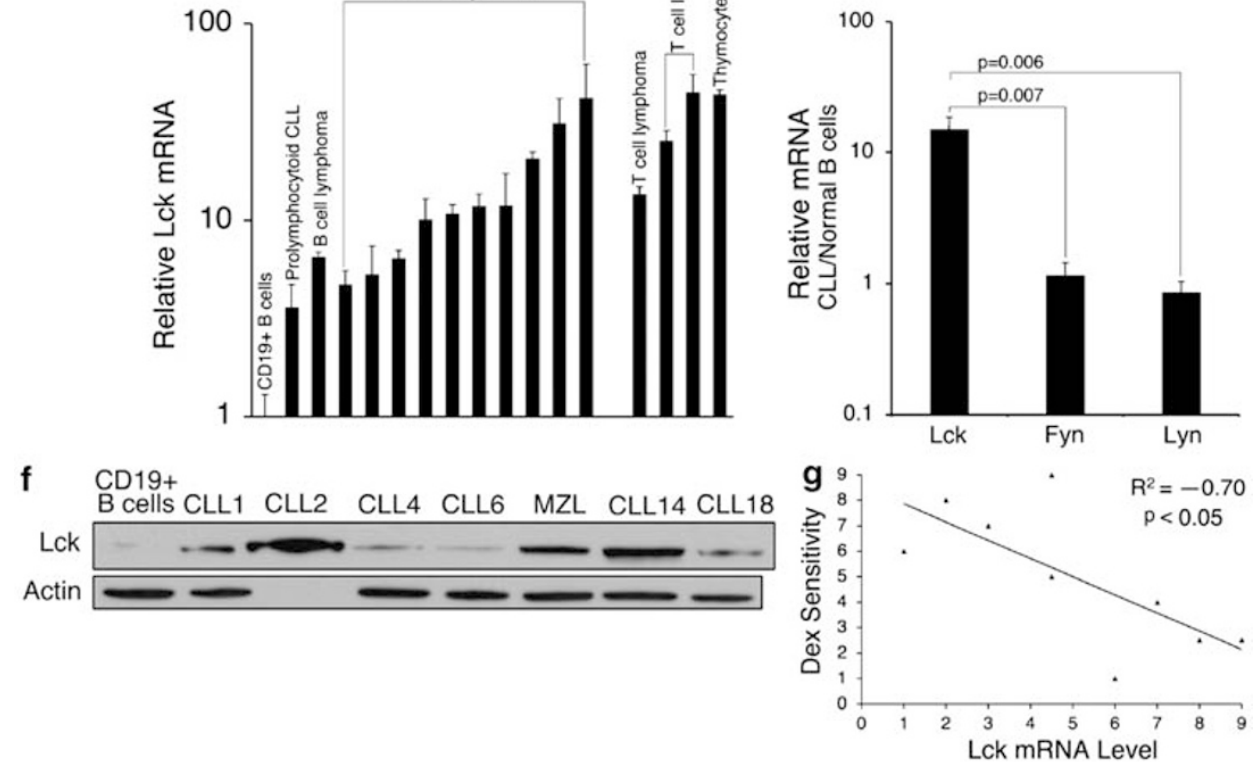

Figure 7 Aberrant Lck expression correlates with resistance to dexamethasone in CLL. (a) Representative single cell calcium traces in unstimulated PBLs from CLL2 showing that these cells undergo ligand-independent signaling. Ligand-independent calcium oscillations were detected in three of three CLL patient samples. (b) PBLs from CLL14 $\left(2 \times 10^{6}\right.$ cells per $\left.\mathrm{ml}\right)$ were treated with vehicle $\left(0.1 \%\right.$ ethanol) or $10^{-6} \mathrm{M}$ dexamethasone for $24-96 \mathrm{~h}$. (c) MEC1 cells $\left(2 \times 10^{5}\right.$ cells per ml) were treated with vehicle or $10^{-6} \mathrm{M}$ dexamethasone for $24 \mathrm{~h}$. Cell viability was measured in triplicate by trypan blue dye exclusion. Similar results were obtained by MTS assay. (d) Lck mRNA was measured by real-time PCR in 10 freshly isolated primary CLL samples and in PBLs from a patient with circulating marginal zone lymphoma. Lck was also measured in the prolymphocytoid CLL line MEC1, primary thymocytes, WEHI7.2, CEMC7, and Jurkat cells. All values were measured in triplicate relative to normal B cells. $\beta$-Actin was used as an endogenous control for each PCR reaction. (e) Fyn and Lyn were measured as in $\mathbf{d}$. Values represent the mean change in mRNA expression relative to normal $B$ cells. Significance was determined by Student's t-test. (f) Lck protein was measured by western blotting in six freshly isolated primary CLL samples. $\beta$-Actin was used as a loading control (lysate from CLL2 was not loaded in lane three due to insufficient sample volume). (g) A scatter-plot showing a significant negative correlation between Lck mRNA level and response to dexamethasone. Lck mRNA was measured as in $\mathbf{d}$ ( $x$ axis) and response to dexamethasone ( $y$ axis) was determined by calculating fold change in cell killing of CLL cells $\left(10^{-6} \mathrm{M}\right.$ dex, $\left.24 \mathrm{~h}\right)$. The scatter-plot shows the Spearman's rank order assigned for each variable pair $(N=9)$. The correlation coefficient is $-0.700(P<0.05)$. Data are representative of multiple independent experiments. Error bars indicate the difference between maximum and mean values from triplicate measurements or the S.E.M from real-time PCR and viability data, respectively.

and overall cell killing in response to dexamethasone (Figure 7g).

Dasatinib enhances glucocorticoid sensitivity and apoptosis in primary CLL cells. In stark contrast to glucocorticoid-sensitive cells, Lck expression was not downregulated by dexamethasone in CLL (Figure $8 a$ and b). In fact, Lck was modestly elevated by dexamethasone, which in turn, led to increased Lck phosphorylation at Y394 (Figure 8b). However, when cells were simultaneously treated with $100 \mathrm{nM}$ dasatinib, Lck phosphorylation was suppressed (Figure 8b). This suggests that, by inhibiting Lck phosphorylation, dasatinib compensates for a high level of Lck in the presence of dexamethasone. To ensure that
CLL cells responded to glucocorticoid-mediated changes in gene expression, we measured the level of an unrelated protein Txnip, which we previously reported to be upregulated by dexamethasone in WEHI7.2 cells and primary thymocytes by a GR-dependent mechanism. ${ }^{31}$ Txnip was also upregulated by dexamethasone in CLL cells within $3 \mathrm{~h}$ (Figure 8c), suggesting that glucocorticoid resistance in CLL is not due to an aberration in cellular uptake of dexamethasone or GR-mediated changes in gene transcription.

Next, we assessed whether dasatinib would enhance sensitivity to dexamethasone in seven primary CLL samples as well as peripheral blood lymphocytes isolated from a patient with circulating mantle cell lymphoma (leukemic form). We found that dasatinib significantly enhanced the response 
a

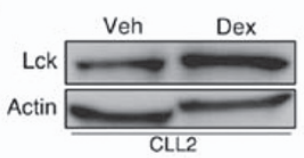

d

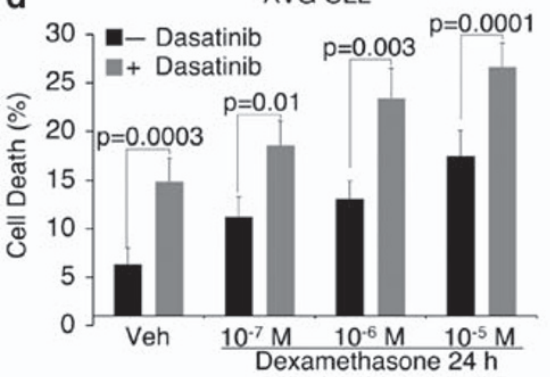

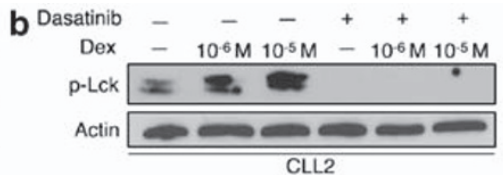

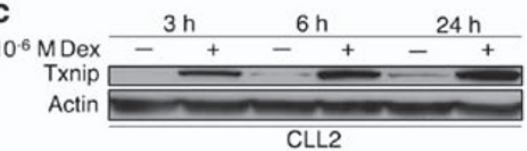

CLL2 e CLL14 f

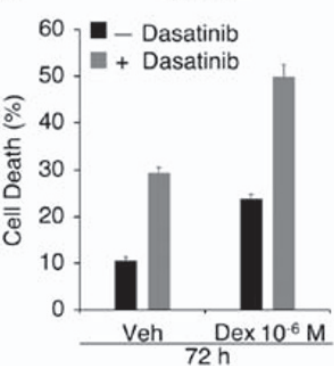

f MEC1

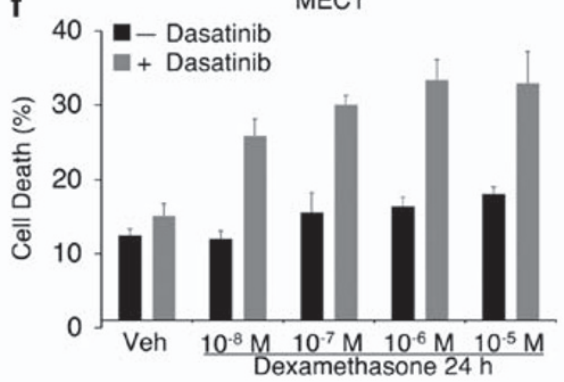

g

CLL6
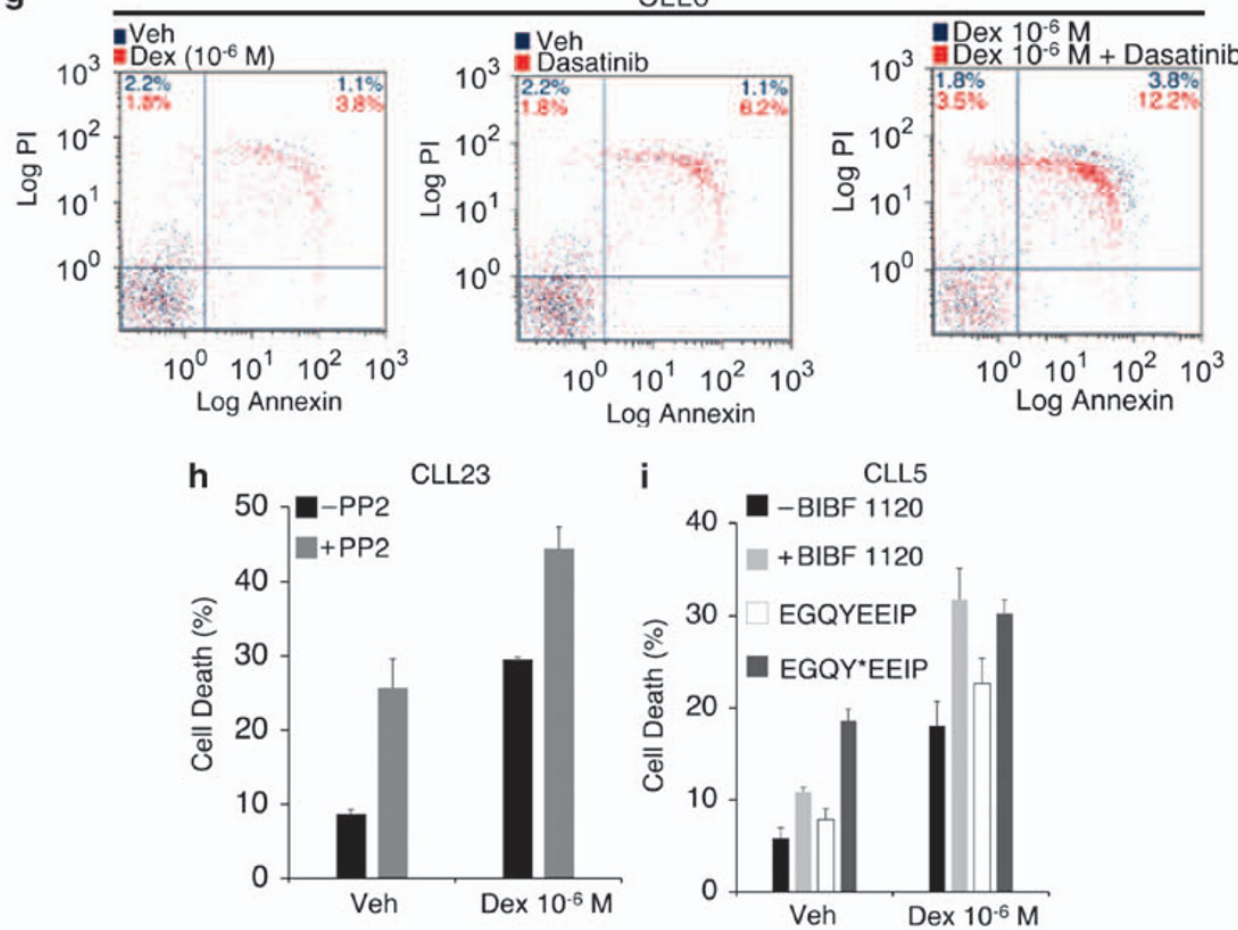

Figure 8 Dasatinib enhances glucocorticoid sensitivity and apoptosis in primary CLL cells. ( $\mathbf{a}$ and $\mathbf{b})$ PBLs from CLL2 were treated with vehicle $\left(0.1 \%\right.$ ethanol) or $10^{-6} \mathrm{M}$ dexamethasone or with vehicles ( $0.1 \%$ ethanol and $0.01 \%$ DMSO), dexamethasone, $100 \mathrm{nM}$ dasatinib or both for $24 \mathrm{~h}$. Total Lck and phospho-Lck (Y394) were measured by western blotting (note that the antibody used to detect phospho-Lck may also crossreact with phospho-Lyn). $\beta$-Actin was used as a loading control. (c) PBLs from CLL2 were treated with vehicle or dexamethasone $\left(10^{-6} \mathrm{M}\right)$ for 3,6 , and $24 \mathrm{~h}$ and GR-responsive protein Txnip was measured by western blotting to control for glucocorticoid uptake and GR functionality. (d) CLL cells and PBLs from a patient with leukemic mantle cell lymphoma were incubated in media containing vehicles $(0.1 \%$ ethanol and $0.01 \%$ DMSO), dexamethasone, $100 \mathrm{nM}$ dasatinib, or both for $24 \mathrm{~h}$. Values represent the mean from treated and control samples. Statistical significance was determined by Student's $t$-test. (e) PBLs from CLL14 were treated as in d with $10^{-6} \mathrm{M}$ dexamethasone for $72 \mathrm{~h}$. (f) MEC1 cells were treated as in $\mathbf{d}$ for $24 \mathrm{~h}$. (g) PBLs from CLL6 were treated as in $\mathbf{d}$ with $10^{-6}$ $\mathrm{M}$ dexamethasone for $24 \mathrm{~h}$. Apoptosis was determined by flow cytometric analysis of Annexin $\mathrm{V}$ and propidium iodide-stained cells. Control experiments are represented in blue dots. Experimental treatments are overlaid in red dots. (h) PBLs from CLL23 were treated with $10^{-6} \mathrm{M}$ dexamethasone and $10 \mu \mathrm{M} \mathrm{PP2}$ for $72 \mathrm{~h}$. (i) PBLs from CLL5 were treated with vehicles $\left(0.1 \%\right.$ ethanol and $0.005 \%$ DMSO), $10^{-6} \mathrm{M}$ dexamethasone, $50 \mathrm{nM} \mathrm{BIBF} 1120$, or both for $24 \mathrm{~h}$. Cells were also treated with $0.1 \%$ ethanol or $10^{-6} \mathrm{M}$ dexamethasone in the presence of either nonphosphorylated (control) EGQYEEIP or phosphorylated EGQY*EEIP $\mathrm{H}_{2} \mathrm{O}$ soluble peptides (200 nM) for $24 \mathrm{~h}$. Cell death was measured in triplicate by trypan blue dye exclusion. (e) Data are representative of multiple independent experiments. Error bars represent the S.E.M.

to dexamethasone at therapeutically relevant concentrations ranging from $10^{-7}$ to $10^{-5} \mathrm{M}$ (Figure $8 \mathrm{~d}$ ). By $72 \mathrm{~h}$, dasatinib had increased the response to dexamethasone by greater than twofold and induced over $50 \%$ cell killing (Figure 8e). The effect on MEC1 cells was similar given that dasatinib also enhanced cell death by approximately twofold after $24 \mathrm{~h}$ of treatment with increasing concentrations of dexamethasone (Figure 8f). Moreover, the combination of both agents more than tripled the amount of dead apoptotic (that is, Annexin $\mathrm{V}$ and propidium iodide positive) cells (Figure $8 \mathrm{~g}$ ). 
To control for potentially nonspecific effects of dasatinib, we also treated CLL cells with a combination of dexamethasone and the Src inhibitor PP2, as well as the phosphopeptide EGQY^EEIP, where the asterisk denotes a phosphorylated tyrosine residue (Figure $8 \mathrm{~h}$ and $\mathrm{i}$ ). This peptide, derived from hamster polyoma middle $\mathrm{T}$ antigen, binds to Lck at a high affinity relative to other Src proteins. ${ }^{37,38}$ Because the $\mathrm{SH} 2$ domain of Lck is required for TCR signaling, ${ }^{39,40}$ these peptides inhibit Lck by blocking $\mathrm{SH} 2$-mediated ligand interactions. PP2 and the $Y^{\star} E E I$ peptide had some degree of activity as single agents, but both enhanced cell killing in response to dexamethasone (Figure $8 \mathrm{~h}$ and $\mathrm{i}$ ). We also used the compound BIBF 1120, which has approximately one order of magnitude higher selectivity for Lck than other Src family kinases. ${ }^{41}$ BIBF $(50 \mathrm{nM})$ produced similar results, further showing the importance for Lck inhibition (Figure 8i). Thus, we conclude that inhibition of Lck significantly enhances sensitivity to dexamethasone in a model of lymphoid malignancy that is relatively insensitive to glucocorticoid treatment.

\section{Discussion}

Here, we report that Lck protects cells from glucocorticoidinduced apoptosis. In glucocorticoid-sensitive T cells, Lck was downregulated by dexamethasone to inhibit TCR activation and signaling. Because TCR activation antagonizes glucocorticoid-induced apoptosis, ${ }^{9-12}$ we reasoned that the inhibition of Lck would confer sensitivity to dexamethasone. We found that inhibition of Lck by RNA interference (RNAi) or by the small-molecule inhibitor dasatinib enhanced glucocorticoid-induced apoptosis in lymphoid cells, and particularly in primary CLL cells that were partially resistant to dexamethasone. CLL represents a clinically relevant model of lymphoid malignancy because synthetic glucocorticoids, such as prednisone and dexamethasone, are widely used in combination with other chemotherapeutic agents for treating aggressive or refractory CLL.

Previous studies have shown that glucocorticoids rapidly inhibit Lck by a nongenomic mechanism involving interactions between the ligand-bound GR and TCR signaling complex. ${ }^{22,23}$ In addition, it has been shown that dexamethasone redistributes Lck out of lipid rafts after T-cell activation, thereby attenuating its activity. ${ }^{19}$ Although these studies unequivocally show that glucocorticoids inhibit Lck and other Src family kinases by distinct mechanisms, this is the first report providing evidence that Lck transcript and protein levels are downregulated by dexamethasone in a GR-dependent manner.

This finding was initially discovered from microarray analysis of dexamethasone-treated cells. In primary thymocytes, Lck was among a subset of genes that were downregulated by a signal $\log _{2}$ ratio of $>2.5$ (that is, greater than sixfold repression). In addition, we show that Lck expression was downregulated at the protein level in mouse lymphoma lines WEHI7.2 and S49A.2, primary thymocytes, and the human T-ALL cell line CEMC7, which is also sensitive to glucocorticoid-induced apoptosis. ${ }^{42}$ However, Lck transcript levels were not reported to be differentially expressed in primary ALL cells treated with prednisolone ${ }^{43}$ or after in vivo treatment with glucocorticoid-based monotherapy. ${ }^{44}$ Yet, a recent study by Mansha et al., found that the Src-like adaptor protein (SLAP), a negative regulator of TCR signaling with significant homology to Lck, ${ }^{45}$ was upregulated by dexamethasone exclusively in glucocorticoid-sensitive ALL cell lines. ${ }^{46}$ Thus, SLAP may be upregulated in B- or T-ALL to circumvent lymphocyte activation or Lck activity. Moreover, it is likely that the regulation of Lck in lymphocytic leukemias is heterogeneous. For example, in this report, we observed that Lck expression was not downregulated by dexamethasone in CLL cells, but was modestly elevated.

Of particular interest were other genes that were downregulated by dexamethasone that are part of the TCR signaling pathway. First, CD3 $\varepsilon$ and CD3 $\gamma$ polypeptides were both downregulated in primary thymocytes. Although decreased expression of CD3 may contribute to glucocorticoid-mediated inhibition of TCR signaling, our RNAi experiments clearly show that the downregulation of Lck alone is sufficient to inhibit TCR-induced calcium oscillations. Second, MEK was downregulated by dexamethasone at the transcript level. Although we did not confirm whether glucocorticoids directly affect MEK levels, this result may provide an additional explanation for why dexamethasone and dasatinib have synergistic activity, given that dasatinib effectively inhibits MEK phosphorylation in T cells. ${ }^{33}$ Finally, we observed that multiple proteins that make up the TCR signaling pathway were downregulated by dexamethasone. In particular, Fyn and ZAP-70 levels were decreased $24 \mathrm{~h}$ after glucocorticoid treatment. Adaptor proteins LAT and SLP-76 were also downregulated by dexamethasone, although this effect was far more pronounced in the presence of dasatinib. These observations further support the concept that glucocorticoids strongly inhibit TCR signal transduction by negatively regulating multiple components of the pathway.

Our results suggest that the downregulation of Lck by dexamethasone does not directly mediate glucocorticoidinduced apoptosis in T cells. However, it is likely that the downregulation of Lck by dexamethasone contributes to cell death and apoptosis by blocking lymphocyte receptor signaling. Because it has been previously shown that MEK and ERK are both necessary and sufficient to inhibit glucocorticoidinduced apoptosis in immature T cells, ${ }^{11}$ we anticipate that Lck inhibition results in the loss of MEK and ERK activation, thereby increasing glucocorticoid sensitivity. The direct influence of MEK and ERK activation on glucocorticoid sensitivity has been documented in other studies, ${ }^{12,47}$ and supported in part by our result that MEK $1 / 2$ phosphorylation is virtually nondetectable in the presence of dexamethasone and dasatinib.

Although dasatinib as a single agent had some cytotoxic effect in CLL cells, the degree of cell killing was variable between patient samples and was relatively modest at a concentration of $100 \mathrm{nM}$. A recent study showed that the $\mathrm{IC}_{50}$ of dasatinib in $18 \mathrm{CLL}$ samples ranged from 0.78 to $53.3 \mu \mathrm{M}$. $^{48}$ Although CLL cells are relatively insensitive to dasatinib alone, it is likely that Lck may contribute, in part, to their survival. For example, CLL cells are partially characterized by increased BCR signaling events, ${ }^{35,36}$ including elevated levels of phosphotyrosine and cytosolic calcium, which are thought to facilitate cell survival. ${ }^{49,50}$ These events correlate with aberrant expression of $\mathrm{Lck}^{29}$ and constitutive expression 
of its B-cell homolog Lyn, ${ }^{36}$ both of which regulate BCR activity. Moreover, our results suggest that other Lck inhibitors (for example, PP2, Y^EEI peptide, and BIBF 1120) also have some degree of cytotoxic activity and all three molecules synergize with dexamethasone. The peptide sequence $E G Q Y^{\star} E E I P$ was specifically designed to bind the $\mathrm{SH} 2$ domain of $\mathrm{LCk}^{37,38}$ and derivatives of these peptides have previously been shown to inhibit cell proliferation in 293T cells. ${ }^{51}$ BIBF 1120 specifically implicates the involvement of Lck because it is $\sim 10$-fold more selective for Lck than other Src kinases. ${ }^{41}$

The most profound cytotoxic responses in CLL cells were observed when dasatinib and dexamethasone were used in combination. Importantly, although glucocorticoids are commonly used to treat lymphoid malignancy, complete responses in CLL lag behind that of ALL and multiple myeloma. ${ }^{1,34,52,53}$ CLL cells were relatively insensitive to dexamethasone when treated ex vivo, and their degree of resistance was positively correlated with Lck expression. In addition, CLL cells were resistant to dexamethasonemediated downregulation of Lck, which was not due to defects in glucocorticoid uptake or aberrations in the GR. Thus, even in the presence of dexamethasone, total and phosphorylated Lck were elevated. Thus, we argue that the high level of Lck in CLL contributes to glucocorticoid resistance in these cells, as $\mathrm{Src}$ kinase inhibitors sensitize them to dexamethasone.

Collectively, our data indicate that Lck functions to antagonize glucocorticoid-induced apoptosis. Because inhibition of Lck sensitizes cells to the cytotoxic effects of dexamethasone, small-molecule inhibitors of Lck should be considered for treating glucocorticoid-resistant malignancies.

\section{Materials and Methods}

Reagents and antibodies. Dexamethasone and RU486 (mifepristone) were purchased from Sigma-Aldrich (St Louis, MO, USA). Dasatinib (BMS-354825, Sprycel) was purchased from LC laboratories (Woburn, MA, USA). PP2 was purchased from Calbiochem (EMD Chemicals, Darmstadt, Germany). BIBF 1120 was purchased from Selleck Chemicals (Houston, TX, USA). Peptides were synthesized by Genscript (Piscataway, NJ, USA) and were $>95 \%$ pure, as assessed by HPLC and mass spectrometry.

The following primary antibodies were used in this study: Fyn (FYN3), Lck (3A5), and Lyn (44) (Santa Cruz Biotechnology, Santa Cruz, CA, USA); Phospho-Lck Y394 (Src Y416, 2101), Phospho-Lck Y505 (2751), ZAP-70 (D1C10E XP), SLP-76 (4958), LAT (9166), Phospho-MEK1/2 S217/S221 (41G9), and Phospho-ERK1/2 T202/Y204 (D13.14.4E), (Cell Signaling Technology, Danvers, MA, USA); antimouse CD3\& (145-2C11) (BD Biosciences, San Jose, CA, USA); Txnip (VDUP-1 C-term) (Invitrogen, Carlsbad, CA, USA); $\beta$-actin (AC-15) (Sigma-Aldrich).

Cell culture. WEHI7.2 cells were cultured in DMEM supplemented with $10 \%$ fetal calf serum, L-glutamine $(2 \mathrm{mM})$, and nonessential amino acids $(100 \mu \mathrm{M})$. MEC1 cells were cultured in IMDM supplemented with $10 \%$ fetal bovine serum, L-glutamine $(2 \mathrm{mM})$, and nonessential amino acids $(100 \mu \mathrm{M})$. CEMC7 and Jurkat cells were cultured in RPMI medium supplemented with 10\% fetal bovine serum, L-glutamine $(2 \mathrm{mM})$, and nonessential amino acids $(100 \mu \mathrm{M})$.

Isolation of primary cells. Peripheral blood from patients diagnosed with CLL, circulating marginal zone lymphoma, or mantle cell lymphoma (leukemic form) was obtained in accordance with IRB-approved protocols (ICC2902/11-02-28) from the Case Western Reserve University Cancer Center and the University Hospitals of Cleveland Ireland Cancer Center. Mononuclear cells were separated by ficoll-hypaque centrifugation, washed in PBS, and lysed for RNA or protein analysis or cultured in RPMI medium supplemented with $10 \%$ fetal bovine serum, L-glutamine $(2 \mathrm{mM})$, and nonessential amino acids $(100 \mu \mathrm{M})$. The mean and median WBC count for all leukemia/lymphoma samples $(N=14)$ was 124000 and 40000 cells per $\mu$, respectively. Normal CD19 + B cells were pooled from three healthy individuals between 26 and 32 years of age, in accordance with IRB-approval (as above). Mononuclear cells were separated by ficoll-hypaque centrifugation, and further isolation of $B$ and $T$ cells was achieved by magnetic separation using CD19 microbeads (Miltenyi Biotec, Bergisch Gladbach, Germany). RNA from purified normal $B$ cells was purchased from Miltenyi Biotec.

Primary thymocytes were obtained from young adult B6 mice in accordance with IACUC-approved protocol 2007-0049. Cells were filtered through a nylon mesh into RPMI medium supplemented with $10 \%$ fetal bovine serum, L-glutamine $(2 \mathrm{mM})$, and nonessential amino acids $(100 \mu \mathrm{M})$.

Microarrray analysis. Complementary DNAs from vehicle- or dexamethasone-treated cells were transcribed into biotinylated cRNAs and hybridized to Affymetrix GeneChips (Affymetrix, Santa Clara, CA, USA) as previously described. $^{31,32}$

RNA isolation, reverse transcription, and qPCR. Total RNA was isolated by conventional phenol/chloroform methods using Trizol reagent (Invitrogen). RNA was precipitated in isopropanol, washed in ethanol, and dissolved in RNase-free water. All RNA samples were quantified by measuring optical density at 260 and $280 \mathrm{~nm}$. Total RNA was reverse transcribed using the TaqMan Gold RT-PCR kit (Applied Biosystems, Foster City, CA, USA). cDNAs generated from reverse transcription reactions were combined with PCR master mix and TaqMan primers and probes (Applied Biosystems) specific for Fyn, Lck, Lyn, or $\beta$-actin. All reactions were amplified in a 7500 fast real-time PCR thermal-cycler (Applied Biosystems). Each sample was quantified by the relative quantification (that is, $2^{-\Delta \Delta C t}$ ) method using $\beta$-actin as the reference gene.

Western blotting. Whole cell lysates were obtained by resuspending cell pellets in cold SDS sample buffer. All samples were subjected to the Bradford assay in which total protein was quantified by obtaining a standard curve using known concentrations of bovine serum albumin. The absorbance of each lysate was measured at $595 \mathrm{~nm}$ in triplicate. Equal concentrations of protein were then loaded onto an SDS gel, transferred to a PVDF membrane, blocked in milk or bovine serum albumin solution, incubated with primary and secondary antibodies, and visualized by chemiluminescence. The appropriate bands were quantified by densitometry. $\beta$-actin was used as a loading control.

Cell viability. Cell viability after drug treatments was assessed by trypan blue dye exclusion and also by measuring mitochondrial integrity after incubation with the MTT analog MTS (Promega, Madison, WI, USA). For the latter, equal concentrations of cells were plated in triplicate and incubated with MTS reagent for 2-3 h. Absorbance was measured at $490 \mathrm{~nm}$ in a 96 -well plate reader. The $\mathrm{IC}_{50}$ was calculated by plotting the data as a logarithmic function of $(\mathrm{x})$ when viability was equal to $50 \%$.

Apoptosis assays. Apoptosis was determined by measuring membrane translocation of phosphatidylserine by Annexin V staining. Annexin V-and/or propidium iodide-positive cells were assessed by flow cytometry using an EPICS XL-MCL flow cytometer (Beckman Coulter, Pasadena, CA, USA). All flow cytometry data were analyzed using FlowJo 8.8.4 for Macintosh (Treestar, Ashland, OR, USA).

Caspase-3 activity was measured from nondenatured whole cell lysates containing $\mathrm{NaCl}(150 \mathrm{mM})$, EDTA $(10 \mathrm{mM})$, Chaps $(1 \%)$, and protease and phosphatase inhibitor cocktails. Protein $(100 \mu \mathrm{g})$ was added to Caspase buffer containing Tris- $\mathrm{Cl}(50 \mathrm{mM}), \mathrm{KCl}(100 \mathrm{mM})$, Sucrose $(10 \%)$, Chaps (1\%), and DTT $(5 \mathrm{mM})$. Fluorogenic Caspase-3 substrate $(100 \mu \mathrm{M})$ (Calbiochem, San Diego, CA, USA) was added to the protein mixture and incubated for $1 \mathrm{~h}$ at $37^{\circ} \mathrm{C}$. Fluorescence was measured in a 96-well plate reader.

Apoptotic nuclear morphology was assessed by staining cells with Hoechst $33342(10 \mu \mathrm{g} / \mathrm{ml})$ for $15 \mathrm{~min}$. Cells were visualized by epifluorescence microscopy (Zeiss axiovert S100) using a $\times 40$ fluorescent oil objective (Carl Zeiss AG, Oberkochen, Germany) and excitation and emission wavelengths of 485 and $535 \mathrm{~nm}$, respectively. Images were obtained using a charge-coupled device camera (Hamamatsu Photonics, Shizuoka, Japan) and digitally converted by Simple PCI software (Hamamatsu Photonics)

Single cell calcium measurements. Lymphocytes were weakly adhered to poly-L-lysine-coated coverslips at concentrations ranging from $7.5 \times 10^{5}$ cells per 
$\mathrm{ml}$ (WEHI7.2) to $2 \times 10^{6}$ cells per $\mathrm{ml}$ (CLL). Once adhered, cells were loaded with the ratiometric calcium dye fura-2AM for $45 \mathrm{~min}$ and de-esterified in calcium BSS buffer $\left(\mathrm{CaCl}_{2}, 1.5 \mathrm{mM}\right)$ for $30 \mathrm{~min}$. Cells were visualized using a $\times 20$ fluorescent objective and Zeiss axiovert $\mathrm{S} 100$ microscope (Carl Zeiss AG). Excitation wavelengths were programmed to alternate at 340 and $380 \mathrm{~nm}$ at $1 \mathrm{~s}$ intervals (for further details see Zhong et al.). ${ }^{54}$

RNA interference. pLKO.1 lentiviral shRNA vectors containing target sequences for Lck (or Fyn) (Open Biosystems, Huntsville, AL, USA) were cotransduced into $293 \mathrm{~T}$ cells along with pMD2G (env) and pR8.74 (gag and pol) vectors to generate viral particles. Cell culture media were assessed for viral titers 24 and $48 \mathrm{~h}$ posttransduction. Viral particles obtained at 24 and $48 \mathrm{~h}$ were combined and incubated with WEHI7.2 cells, with puromycin as a marker for selection. WEHI7.2 cells were grown continuously in the presence of puromycin to generate stable knockdown cells. For transient knockdown of Lck, $5 \times 10^{7}$ cells were resuspended in serum-free media and mixed with nontargeting control or Lck-specific siRNA oligonucleotide SMARTpools (Dharmacon, Lafayette, CO, USA) at a concentration of $1 \mu \mathrm{M}$. Cells were electroporated with a single $140 \mathrm{~V}$, $10 \mathrm{~ms}^{2}$ wave pulse in a $0.2 \mathrm{~cm}$ cuvette, transferred to fresh media containing serum, and incubated for $24 \mathrm{~h}$.

Statistical analysis. A Student's $t$-test was used to assess statistical differences between groups. A two-tailed $P$-value of $<0.05$ was the threshold for significance. A Spearman's rank correlation was used to determine statistical dependence between Lck mRNA expression and dexamethasone sensitivity. Statistical tests were performed using Microsoft Excel 2004 for Macintosh.

\section{Conflict of interest}

The authors declare no conflict of interest.

Acknowledgements. We would like to thank Michael Sramkoski of the Case Comprehensive Cancer Center flow cytometry core facility for providing us with technical expertise and advice. We would also like to acknowledge that this work was supported by $\mathrm{NCl}$ research grants $5 \mathrm{R} 01 \mathrm{CA} 042755$ (C.W.D.) and by T32 CA059366 (M.W.H.).

1. Gaynon PS, Carrel AL. Glucocorticosteroid therapy in childhood acute lymphoblastic leukemia. Adv Exp Med Biol 1999; 457: 593-605.

2. Smets LA, Salomons G, van den Berg J. Glucocorticoid induced apoptosis in leukemia. Adv Exp Med Biol 1999; 457: 607-614.

3. Kofler R. The molecular basis of glucocorticoid-induced apoptosis of lymphoblastic leukemia cells. Histochem Cell Biol 2000; 114: 1-7.

4. Herold MJ, McPherson KG, Reichardt HM. Glucocorticoids in T cell apoptosis and function. Cell Mol Life Sci 2006; 63: 60-72.

5. Schmidt S, Rainer J, Ploner C, Presul E, Riml S, Kofler R. Glucocorticoid-induced apoptosis and glucocorticoid resistance: molecular mechanisms and clinical relevance. Cell Death Differ 2004; 11 (Suppl 1): S45-S55.

6. Cidlowski JA, King KL, Evans-Storms RB, Montague JW, Bortner CD, Hughes Jr FM. The biochemistry and molecular biology of glucocorticoid-induced apoptosis in the immune system. Recent Prog Horm Res 1996; 51: 457-490; discussion 490-1.

7. Necela BM, Cidlowski JA. Mechanisms of glucocorticoid receptor action in noninflammatory and inflammatory cells. Proc Am Thorac Soc 2004; 1 : 239-246.

8. Distelhorst CW. Recent insights into the mechanism of glucocorticosteroid-induced apoptosis. Cell Death Differ 2002; 9: 6-19.

9. Tolosa E, Ashwell JD. Thymus-derived glucocorticoids and the regulation of antigenspecific T-cell development. Neuroimmunomodulation 1999; 6: 90-96.

10. Iwata M, Hanaoka S, Sato K. Rescue of thymocytes and T cell hybridomas from glucocorticoid-induced apoptosis by stimulation via the $\mathrm{T}$ cell receptor/CD3 complex: a possible in vitro model for positive selection of the T cell repertoire. Eur J Immunol 1991; 21: 643-648.

11. Jamieson CA, Yamamoto KR. Crosstalk pathway for inhibition of glucocorticoid-induced apoptosis by T cell receptor signaling. Proc Natl Acad Sci USA 2000; 97: 7319-7324.

12. Tsitoura DC, Rothman PB. Enhancement of MEK/ERK signaling promotes glucocorticoid resistance in CD4+ T cells. J Clin Invest 2004; 113: 619-627.

13. Palacios EH, Weiss A. Function of the Src-family kinases, Lck and Fyn, in T-cell development and activation. Oncogene 2004; 23: 7990-8000.

14. Mustelin T, Tasken K. Positive and negative regulation of T-cell activation through kinases and phosphatases. Biochem J 2003; 371: 15-27.

15. Lewis RS. Calcium signaling mechanisms in T lymphocytes. Annu Rev Immunol 2001; 19: 497-521.
16. Harr MW, Rong Y, Bootman MD, Roderick HL, Distelhorst CW. Glucocorticoid-mediated inhibition of Lck modulates the pattern of T cell receptor-induced calcium signals by downregulating inositol 1,4,5-trisphosphate receptors. J Biol Chem 2009; 284: 31860-31871.

17. Crabtree GR. Generic signals and specific outcomes: signaling through $\mathrm{Ca} 2+$, calcineurin, and NF-AT. Cell 1999; 96: 611-614.

18. Iwata M, Ohoka $Y$, Kuwata $T$, Asada A. Regulation of $T$ cell apoptosis via $T$ cell receptors and steroid receptors. Stem Cells 1996; 14: 632-641.

19. Van Laethem F, Baus E, Smyth LA, Andris F, Bex F, Urbain J et al. Glucocorticoids attenuate T cell receptor signaling. J Exp Med 2001; 193: 803-814.

20. Baus E, Andris F, Dubois PM, Urbain J, Leo O. Dexamethasone inhibits the early steps of antigen receptor signaling in activated T lymphocytes. J Immunol 1996; 156: 4555-4561.

21. Northrop JP, Crabtree GR, Mattila PS. Negative regulation of interleukin 2 transcription by the glucocorticoid receptor. J Exp Med 1992; 175: 1235-1245.

22. Lowenberg M, Tuynman J, Bilderbeek J, Gaber T, Buttgereit F, van Deventer S et al. Rapid immunosuppressive effects of glucocorticoids mediated through Lck and Fyn. Blood 2005; 106: 1703-1710.

23. Lowenberg M, Verhaar AP, Bilderbeek J, Marle J, Buttgereit F, Peppelenbosch MP et al. Glucocorticoids cause rapid dissociation of a T-cell-receptor-associated protein complex containing LCK and FYN. EMBO Rep 2006; 7: 1023-1029.

24. Abraham KM, Levin SD, Marth JD, Forbush KA, Perlmutter RM. Thymic tumorigenesis induced by overexpression of p56lck. Proc Natl Acad Sci USA 1991; 88: 3977-3981.

25. Jucker $M$, Abts $H$, Eick D, Lenoir GM, Tesch $H$. Over-expression of Ick in Burkitt's lymphoma cell lines. Leukemia 1991; 5: 528-530.

26. Von Knethen A, Abts $H$, Kube D, Diehl V, Tesch $H$. Expression of p56lck in B-cell neoplasias. Leuk Lymphoma 1997; 26: 551-562.

27. Abts H, Jucker M, Diehl V, Tesch H. Human chronic lymphocytic leukemia cells regularly express mRNAs of the protooncogenes Ick and c-fgr. Leuk Res 1991; 15: 987-997.

28. Rouer E, Dreyfus F, Melle J, Ribrag V, Benarous R. Selective increase of alternatively spliced Lck transcripts from the proximal promotor in hematopoietic malignancies. Leukemia 1993; 7: 246-250.

29. Majolini MB, D'Elios MM, Galieni P, Boncristiano M, Lauria F, Del Prete G et al. Expression of the T-cell-specific tyrosine kinase Lck in normal B-1 cells and in chronic lymphocytic leukemia B cells. Blood 1998; 91: 3390-3396.

30. al-Ramadi BK, Zhang H, Bothwell AL. Cell-cycle arrest and apoptosis hypersusceptibility as a consequence of Lck deficiency in nontransformed T lymphocytes. Proc Natl Acad Sci USA 1998; 95: 12498-12503.

31. Wang Z, Rong YP, Malone MH, Davis MC, Zhong F, Distelhorst CW. Thioredoxininteracting protein (txnip) is a glucocorticoid-regulated primary response gene involved in mediating glucocorticoid-induced apoptosis. Oncogene 2006; 25: 1903-1913.

32. Wang Z, Malone MH, He H, McColl KS, Distelhorst CW. Microarray analysis uncovers the induction of the proapoptotic BH3-only protein Bim in multiple models of glucocorticoidinduced apoptosis. J Biol Chem 2003; 278: 23861-23867.

33. Schade AE, Schieven GL, Townsend R, Jankowska AM, Susulic V, Zhang $R$ et al. Dasatinib, a small-molecule protein tyrosine kinase inhibitor, inhibits T-cell activation and proliferation. Blood 2008; 111: 1366-1377

34. Faderl S, Ferrajoli A, Frankfurt O, Pettitt A. Treatment of B-cell chronic lymphocytic leukemia with nonchemotherapeutic agents: experience with single-agent and combination therapy. Leukemia 2009; 23: 457-466.

35. Efremov DG, Gobessi S, Longo PG. Signaling pathways activated by antigen-receptor engagement in chronic lymphocytic leukemia B-cells. Autoimmun Rev 2007; 7: 102-108.

36. Contri A, Brunati AM, Trentin L, Cabrelle A, Miorin M, Cesaro L et al. Chronic lymphocytic leukemia B cells contain anomalous Lyn tyrosine kinase, a putative contribution to defective apoptosis. J Clin Invest 2005; 115: 369-378.

37. Eck MJ, Shoelson SE, Harrison SC. Recognition of a high-affinity phosphotyrosyl peptide by the Src homology-2 domain of p56lck. Nature 1993; 362: 87-91.

38. Cousins-Wasti RC, Ingraham RH, Morelock MM, Grygon CA. Determination of affinities for Ick SH2 binding peptides using a sensitive fluorescence assay: comparison between the PYEEIP and PYQPQP consensus sequences reveals context-dependent binding specificity. Biochemistry 1996; 35: 16746-16752.

39. Couture C, Songyang Z, Jascur T, Williams S, Tailor P, Cantley LC et al. Regulation of the Lck SH2 domain by tyrosine phosphorylation. J Biol Chem 1996; 271: 24880-24884.

40. Caron L, Abraham N, Pawson T, Veillette A. Structural requirements for enhancement of T-cell responsiveness by the lymphocyte-specific tyrosine protein kinase p56lck. Mol Cell Biol 1992; 12: 2720-2729.

41. Hilberg F, Roth GJ, Krssak M, Kautschitsch S, Sommergruber W, Tontsch-Grunt U et al. BIBF 1120: triple angiokinase inhibitor with sustained receptor blockade and good antitumor efficacy. Cancer Res 2008; 68: 4774-4782.

42. Norman MR, Thompson EB. Characterization of a glucocorticoid-sensitive human lymphoid cell line. Cancer Res 1977; 37: 3785-3791.

43. Tissing WJ, den Boer ML, Meijerink JP, Menezes RX, Swagemakers S, van der Spek PJ et al. Genomewide identification of prednisolone-responsive genes in acute lymphoblastic leukemia cells. Blood 2007; 109: 3929-3935.

44. Schmidt S, Rainer J, Riml S, Ploner C, Jesacher S, Achmuller $C$ et al. Identification of glucocorticoid-response genes in children with acute lymphoblastic leukemia. Blood 2006; 107: 2061-2069.

45. Sosinowski T, Pandey A, Dixit VM, Weiss A. Src-like adaptor protein (SLAP) is a negative regulator of T cell receptor signaling. J Exp Med 2000; 191: 463-474. 
46. Mansha M, Carlet M, Ploner C, Gruber G, Wasim M, Wiegers GJ et al. Functional analyses of Src-like adaptor (SLA), a glucocorticoid-regulated gene in acute lymphoblastic leukemia Leuk Res 2009; 34: 529-534.

47. Rambal AA, Panaguiton ZL, Kramer L, Grant S, Harada H. MEK inhibitors potentiate dexamethasone lethality in acute lymphoblastic leukemia cells through the pro-apoptotic molecule BIM. Leukemia 2009; 23: 1744-1754.

48. Amrein L, Hernandez TA, Ferrario C, Johnston J, Gibson SB, Panasci L et al. Dasatinib sensitizes primary chronic lymphocytic leukaemia lymphocytes to chlorambucil and fludarabine in vitro. Br J Haematol 2008; 143: 698-706.

49. Kipps TJ. The B-cell receptor and ZAP-70 in chronic lymphocytic leukemia. Best Pract Res Clin Haematol 2007; 20: 415-424.

50. Veldurthy A, Patz M, Hagist S, Pallasch CP, Wendtner CM, Hallek M et al. The kinase inhibitor dasatinib induces apoptosis in chronic lymphocytic leukemia cells in vitro with preference for a subgroup of patients with unmutated IgVH genes. Blood 2008; 112: 1443-1452.

51. Nam NH, Pitts RL, Sun G, Sardari S, Tiemo A, Xie M et al. Design of tetrapeptide ligands as inhibitors of the Src SH2 domain. Bioorg Med Chem 2004; 12: 779-787.

52. Dungarwalla M, Evans SO, Riley U, Catovsky D, Dearden CE, Matutes E. High dose methylprednisolone and rituximab is an effective therapy in advanced refractory chronic lymphocytic leukemia resistant to fludarabine therapy. Haematologica 2008; 93: 475-476.

53. Alexanian R, Dimopoulos MA, Delasalle K, Barlogie B. Primary dexamethasone treatment of multiple myeloma. Blood 1992; 80: 887-890.

54. Zhong F, Davis MC, McColl KS, Distelhorst CW. Bcl-2 differentially regulates $\mathrm{Ca}^{+}$signals according to the strength of $\mathrm{T}$ cell receptor activation. J Cell Biol 2006; 172: $127-137$. 